Bioética

\section{DILEMAS ÉTICOS GERADOS PELA SARS}

A epidemia de SARS (severe acute respiratory syndrome), além de grandes problemas médicos, epidemiológicos e de saúde pública, trouxe também importantes questionamentos éticos. Uma análise dos dilemas éticos surgidos durante a epidemia de SARS em Toronto foi recentemente publicada por um grupo canadense de especialistas de várias áreas, com formação em bioética. Esse grupo identifica 10 valores éticos que devem ser considerados e apresenta cinco casos em que a tomada de decisão se confronta com um dilema ético. $O$ primeiro caso contrapõe a necessidade de quarentena à liberdade do indivíduo. $O$ segundo nos remete ao dilema entre não tornar pública a identificação de um indivíduo infectado, ou seja, o seu direito à privacidade e a proteção de indivíduos que tiveram um contato eventual no transporte público. A identificação pode estigmatizar o indivíduo ou até mesmo criar um preconceito contra uma etnia como o relato feito pelos autores, de que as pessoas passaram a evitar o comércio com os chineses depois da identificação das pessoas que levaram a SARS da China para o Canadá. O terceiro caso trata do dilema de uma enfermeira de terapia intensiva entre a sua obrigação de cuidar de pacientes infectados e risco de adquirir a doença, até mesmo morrer, e também de transmiti-la a seus familiares. Até onde vai a obrigação profissional? $O$ quarto caso discute os "efeitos colaterais" da epidemia para a população sem SARS, ou seja, a não realização de cirurgias e as internações somente em casos de extrema necessidade e sem permissão de visitas. Como balancear os direitos ao atendimento médico dos pacientes com SARS e da população em geral? $\bigcirc$ quinto, e último caso, analisa o problema das viagens aéreas que espalharam a SARS pelo mundo e a necessidade, em uma situação de risco, de todos os países rapidamente compartilharem informações.

\section{Comentário}

Esse artigo mostra que, perante a globalização das doenças infecciosas, devemos nos preparar não somente para um rápido diagnóstico e tratamento, mas também para inevitáveis desafios éticos.

Regina Abdulkader
Referência

Singer PA, Benatar SR, Berstein M, Daar AS, Dickens BM, MacRae SK, et al. Ethics and SARS: lessons from Toronto. BMJ 2003; 327: 1342-4.

\section{Clínica Cirírgica \\ DIVERTÍCULO DUODENAL PERIAMPOLAR E DOENÇA BILIOPANCREÁTICA}

Os divertículos periampolares (DPA) são abaulamentos extra-luminais da mucosa duodenal, adjacente ou contendo a ampola de Vater (papila maior), ou a porção intramural do ducto biliar comum. Os divertículos que se encontram dentro de um raio de 2 a $3 \mathrm{~cm}$ da ampola, mas não contendo a mesma, são chamados de justa-papilares, e a papila que se encontra dentro do divertículo é chamada de intradiverticular. Eles podem estar presentes em $0,16 \%$ a $27 \%$ da população geral e em I $1 \%$ a $23 \%$ das necropsias. Sabe-se que sua incidência aumenta após a sexta década de vida, sendo excepcional antes dos 40 anos.

A relação entre os divertículos periampolares e a litíase da vesícula biliar é freqüentemente sugerida, porém acredita-se que se trata de uma associação incidental e não causal. Sua associação com a litíase da via biliar principal, porém, já é bem estabelecida, ocorrendo desconjugação da bile pelas bactérias do interior do divertículo; os sais biliares livres se associam ao cálcio, formando cristais de bilirrubinato de cálcio e os cálculos.

Considerava-se o divertículo uma contraindicação relativa à papilotomia endoscópica pelo risco de perfuração. Posteriormente, verificou-se que a papilotomia era segura e a hemorragia é a complicação mais freqüente do procedimento.

O divertículo duodenal geralmente não requer tratamento específico. No tratamento operatório da coledocolitíase, o divertículo não exige tratamento ao mesmo tempo. A conduta clássica ao tratamento específico do divertículo é sua ressecção ou inversão. Outra modalidade de tratamento é a duodenojejunostomia em Y-de-Roux, com objetivo de isolar o divertículo do trânsito alimentar, minimizando a estase alimentar em seu interior, reduzindo a chance de colangite e pancreatite.

A relação do divertículo periampolar com neoplasia da via biliar não é bem estabelecida. Lobo et al. demonstraram em sua casuística $5 \%$ de colangiocarcinoma associados ao divertículo. Acredita-se também que o DPA possa participar da patogênese de alguns casos de pancreatite aguda ou crônica.

\section{Comentário}

Os DPA apesar de serem relativamente freqüentes são pouco discutidos na prática clínica. A coexistência dos divertículos com a coledocolitíase dificulta o tratamento endoscópico e aumenta as taxas de complicações, principalmente quando a papila é intradiverticular. O tratamento específico do divertículo, apesar de ter indicação restrita, é acompanhado de complicações, principalmente quando há necessidade do reimplante da papila.

\section{Carlos Roberto Puglia}

Referências

l.Lobo DN, Balfour TW, Iftikhar SY, Rowlands, BJ. Periampullary diverticula and pancreaticobiliary disease. Br J Surg 1999; 86:588-97

2. Zoepf T, Zoepf D, Arnold J. Juxtapapillary dudenal diverticula and biliopancreatic disease. Gantrointest Endosc 2001; 54:61-56.

3. Kennedy RH, Thompson MH. Are duodenal diverticula associated with choledocholithiasis? Gut 1998; 29:1003-6.

4. Egawa N, Kamisawa T, Tu Y, Sakaki N, Tsuruta K, Okamoto A. The role of juxtapapillary doudenal diverticulum in the formation of gallbladder stones. Hepatogastroenterology 1998; 45:917-20.

\section{Emergência e Medicina Intensiva \\ O ÓXIDO NÍTRICO NÄO DEVE SER RECOMENDADO PARA LESÃO PULMONAR AGUDA}

A hipoxemia e a hipertensão pulmonar estão presentes na síndrome do desconforto respiratório agudo (SDRA) e a gravidade de cada uma está intimamente relacionada com a mortalidade. A utilização do óxido nítrico 